\title{
RELATIONSHIPS AMONG COKING COALS AND RELATED COKES CHARACTERISTICS: A STATISTICAL EVALUATION
}

\author{
Jana SERENČíŠOVÁ ${ }^{1)}$, Zdeněk KLIKA ${ }^{1) *}$, Ivan KOLOMAZNÍK ${ }^{1)}$, \\ Lucie BARTOŇOVÁ ${ }^{1)}$ and Pavel BARAN ${ }^{2)}$
}

${ }^{1)} V \check{S} B-$ Technical University of Ostrava, 17. listopadu 15/2172, 70833 Ostrava-Poruba, Czech Republic
${ }^{2)}$ ArcelorMittal Ostrava, Vratimovská 689, 70702 Ostrava-Kunčice, Czech Republic

*Corresponding author's e-mail: zdenek.klika@vsb.cz

\section{ARTICLE INFO}

Article history

Received 2 September 2018

Accepted 5 October 2018

Available online 10 October 2018

\section{Keywords:}

Coal

Coke

CRI

CSR

Multivariate statistics

\begin{abstract}
From 61 coking coals, 36 coal blends were prepared. Using a pilot coke oven, cokes were prepared from both 61 coking coals (Type I cokes) and 36 coal blends (Type II cokes). Coals were characterized by 14 coal characteristics and cokes by Coke Reactivity Index CRI and Coke Strength after Reaction with $\mathrm{CO}_{2} \mathrm{CSR}$. For the study of mutual statistic relationships among experimentally determined characteristics of coals and cokes, the Factor (FA) and Regression Analyses (RA) were used. FA distributed characteristics of coals and Type I cokes into 4 factors while characteristics of coal blends and Type II cokes were distributed into 7 factors. In case of pure coals and Type I cokes, strong relationships with high correlation coefficients $(\mathrm{R}>|0.60|)$ were more abundant than in case of coal blends and Type II cokes. FA was used for the selection of coal characteristics that influence the coke quality the most significantly. These characteristics were then recalculated by RA for the predictions of CRI/CSR of Type I cokes. Predictions of CRI/CSR of Type II cokes were calculated from coal blends by the same procedure. The comparison of the predicted and experimentally determined CRI and CSR indexes showed much more reliable prediction of CRI/CSR indexes calculated from coals than calculated from coal blends. This study also explains the dominant reasons of this observation.
\end{abstract}

\section{INTRODUCTION}

The selection of coking coals plays a key role in the production of high-quality metallurgical cokes. Coals must be of suitable chemical, physical and technological properties that determine the quality of produced coke (Leonard et al., 1996; Van Krevelen, 1993). The quality of coke mostly depends on the properties of the coking coals and only partially on coking conditions (Prasad et al., 1996). Therefore, the relationships among coal and related coke characteristics were studied by numerous authors (Barriocanal et al., 2003; Díaz-Faes et al., 2007; Díez et al., 2002; Krzesińska et al., 2002; Kumar et al., 2008; Pusz et al., 2003; Sakurovs, 1997; Sakurovs et al., 2007; Todoschuk et al., 2004; Zhang et al., 2004).

The produced coke should exhibit namely high mechanical strength characterized by CSR and low reactivity characterized by CRI index (Koszorek et al., 2009; Sakurovs et al., 2007). A high negative correlation between CRI and CSR was verified by numerous authors (e.g. Koszorek et al., 2009; Menéndez et al., 1999). Many of these correlations were also displayed visually (North et al., 2018). Therefore, for the prediction of the coke quality, some authors propose to calculate only CSR (North et al., 2017; Suresh et al., 2012; Tiwari et al., 2013).
One of the simplest models for the coke quality prediction was based on the mean vitrinite reflectance and the inertinite content in the parent coals (Miura, 1978). For the preparation of the coke with sufficiently high CSR index, some studies recommend using blends of coals with high mean $R_{o}$ values (Chaudhuri et al., 1990; Pusz et al., 2009). Currently, particular attention is paid to coal macerals and optical properties in relation to CRI and CSR indexes (Gupta et al., 2012; Pusz et al., 2009, 2003). For example, the prediction model for the calculation of CRI/CSR based on the reflectance parameters $\left(R_{\max }, R_{\min }\right.$ and bireflectance $\mathrm{R}_{\mathrm{bi}}$ ) showed that higher inertinite content in parent coals ( $\geq 30$ vol. $\%$ ) could produce lowerquality cokes with increased CRI and decreased CSR indexes (Pusz and Buszko, 2012). In addition, the full maceral reflectance parameter (FMR) based on automated microscopy of individual coal grains was modified and a new Combined Coal Index (CCI) has been proposed, which improved the accuracy of coke CSR prediction (Gupta et al., 2012).

Recently, the prediction model based on the additivity law and the optical texture of cokes carbonized from individual coals was developed. Moreover, some corrections of the relative proportions of the individual coals present in coal blends were 
used. A clear cause-and-effect relationship between optical texture and CRI/CSR of the cokes was found, which could be used as a relevant tool for understanding the coal blending and corresponding coke quality (Flores et al., 2017).

Vitrinite reflectance can also be used for the prediction of the quality of cokes derived from coal blends. A novel method of classifying vitrinite reflectance distributions using self-organizing maps was already presented to capture the multimodal nature of coal blends. Despite some limitations, this model seems to be a promising approach for capturing the underlying vitrinite distribution behavior, and for inferring the implications of blending decisions on coke quality (North et al., 2017).

The relationships among CRI/CSR indexes, chemical composition and physical parameters of cokes were also studied using Czech metallurgical cokes; nevertheless, only five of the calculated relationships were statistically significant. Anyway, the highest correlation coefficients were obtained for the relationship between the pycnometer density of cokes and CSR index $(\mathrm{R}=0.925)$ or CRI index $(\mathrm{R}=-0.828)$, which could be used for the prediction of commercial coke quality (Lech et al., 2017).

Promising results of the CRI/CSR prediction of cokes have been shown using models based on multiple coal characteristics. Zhang et al. (2004) presented the model based on $\mathrm{V}^{\mathrm{d}}, \mathrm{A}^{\mathrm{d}}, \mathrm{S}_{\mathrm{t}}$, the caking index $G$ and Gieseler fluidity $\operatorname{lgF}$ parameters, the mineral catalysis index (MCI), including coal rank and plastic properties of coal. Among these models belong also a procedure using Composite Coking Potential (CCP) coefficient with 12 selected parameters of parent coals suggested by Tiwari et al. (2003) and adaptive neurofuzzy inference system (ANFIS) using the functional relationships among numerous coal blend properties and corresponding CSR indexes reported by Suresh et al. (2012). More information and some other models used for the prediction of the coke quality are described in review papers (de Cordova et al., 2016; North et al., 2018).

The aim of this paper is to search for such characteristics of parent coals that can significantly influence the prediction of CRI and CSR indexes, which could be used for the improvement of the commercial cokes quality.

\section{MATERIALS, METHODS, COAL AND COKE CHARACTERISTICS}

For the purpose of this study, the set of 61 coal samples including 7 coal types from the Upper Silesian Coal Basin (Czech Republic and Poland) and 1 from the Appalachian Coal Basin (USA) were used. The samples were selected according to the coalification degree (coal rank) - 5 samples exhibited low volatile matter content $\left(\mathrm{V}^{\text {daf }} \leq 22.0 \%\right)$, 41 samples were medium volatile matter coals $\left(22.0 \%<\mathrm{V}^{\mathrm{daf}}<31.0 \%\right)$ and 15 samples exhibited high volatile matter content $\left(\mathrm{V}^{\mathrm{daf}}>31.0 \%\right.$ ) (ASTM D388-05, 2005). In addition to these samples, other
36 coal blends were prepared by blending the aforementioned coals with the required quality. From these coals (61) and coal blends (36), the cokes were produced in a pilot coke oven under the standard coking conditions. The cokes originating from pure coals were referred to as Type I cokes (61 samples) and the cokes prepared from the coal blends were referred to as Type II cokes (36 samples).

Approximately $500 \mathrm{~kg}$ batches of coals (prepared for the carbonization) were grinded in a pilot coal crusher into fractions lower than $3 \mathrm{~mm}(90 \%)$ and homogenized for 15 minutes. Tested coal batches were inserted into the pilot coke oven with a movable wall and the stamp charging was used. The density of charge (with $10 \%$ humidity) was about $1020 \mathrm{~kg} / \mathrm{m}^{3}$. The coal batches were heated from each side by six electric heating elements to the temperature of $1040{ }^{\circ} \mathrm{C}$ for 22 hours so that the temperature of $1000{ }^{\circ} \mathrm{C}$ in the middle of the charge was achieved. Cokes prepared in the pilot coke oven were then displaced into the quenching car and quenched by water for ca. 10 minutes. The cooled and dry cokes were then subjected to stabilization. The pilot coke oven is used for the verification of the quality and checking the safety of coking process (Corporate Coke Lab Center of ArcelorMittal, Czech Republic).

For the coal and/or coal blend samples, the following characteristics were determined in accordance with ASTM/ISO standards: ash content $\mathrm{A}^{\mathrm{d}}$ (ISO 1171, 2010), volatile matter $\mathrm{V}^{\mathrm{d}}$ (ISO 562, 2010), contraction a and dilation b (ISO 349, 1975), Swelling Index SI (ISO 501, 2012), Gieseler maximum fluidity $F_{\text {max. }}$ (ASTM D2639/D2639M-16, 2016), Alkali Index Alk. I. (Eq. 1), Alkalis (Eq. 2), and Catalytic Index Cat. I. (Eq. 3) (ASTM D4326-13, 2013)

$$
\begin{aligned}
& \text { Alk.I. }=10^{-2} \cdot A^{d} \cdot \text { Cat.I. } \\
& \text { Alkalis }=\mathrm{Na}_{2} \mathrm{O}+\mathrm{K}_{2} \mathrm{O} \\
& \text { Cat.I. }= \\
& \quad=\left(\mathrm{Fe}_{2} \mathrm{O}_{3}+\mathrm{CaO}+\mathrm{MgO}+\mathrm{Na}_{2} \mathrm{O}+\mathrm{K}_{2} \mathrm{O}\right) /\left(\mathrm{SiO}_{2}+\mathrm{Al}_{2} \mathrm{O}_{3}\right)
\end{aligned}
$$

A petrographic analysis of coal (reflectance of vitrinite $\mathrm{R}_{\mathrm{r}}$, vitrinite Vitr, inertinite Inert, liptinite Lipt) was determined according to ISO 7404 (ISO 7404-5, 2009; ISO 7404-3, 2009) and performed using microscopic assembly of Nikon Labophot 2 with a DS-CCD Nikon DS-5M camera equipped with immersion lens with a magnification of 40x and a Märzhäuser motorized scanning stage. Cokes were characterized by Coke Reactivity Index CRI and Coke Strength after Reaction with $\mathrm{CO}_{2}$ CSR (ISO 18894, 2006). Once received the coals, coking in the pilot coke oven and laboratory analyses were performed without delay. Mutual relationship between CRI and CSR values for Type I and II cokes is depicted (Fig. 1) and it indicates a strong negative correlation, which is consistent with $\mathrm{R}^{2}=0.977$ (Menéndez et al., 1999) and $R^{2}=0.953$ (Flores et al., 2017). 


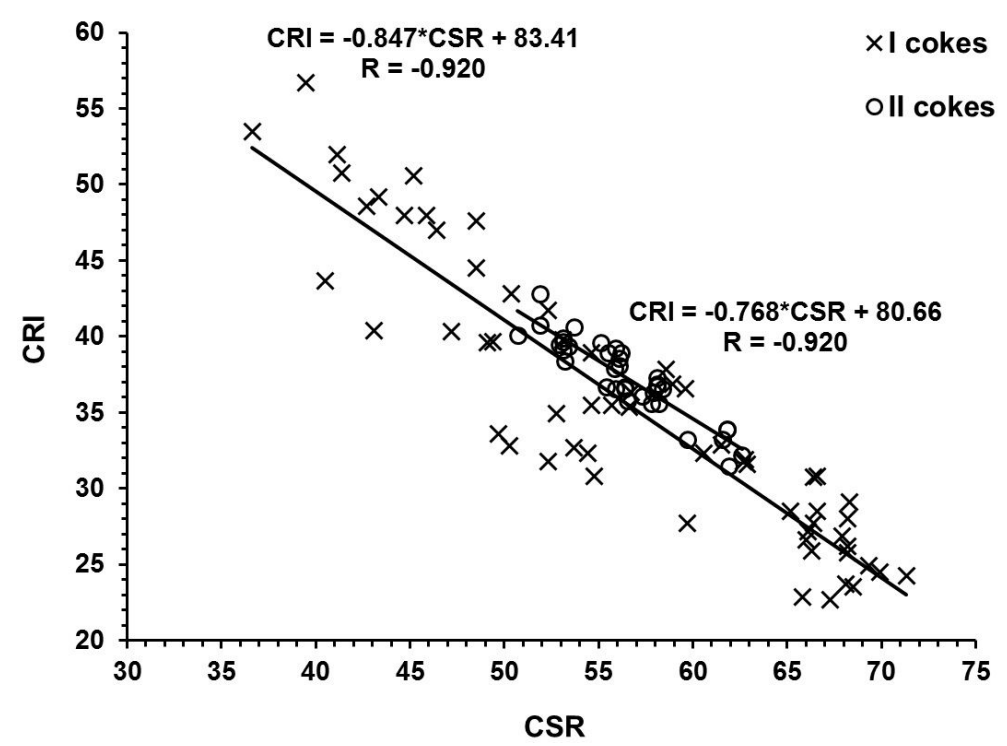

Fig. 1 Experimentally determined Coke Reactivity Index (CRI) vs. Coke Strength after Reaction with $\mathrm{CO}_{2}$ (CSR) of Type I cokes and Type II cokes.

\section{STATISTICAL EVALUATION OF COALS AND COKES PROPERTIES}

\subsection{BASIC STATISTICS}

Experimentally determined characteristics of pure coals and corresponding Type I cokes (61 samples) as well as coal blends and related Type II cokes (36 samples) were evaluated using QC.Expert 2.7 (TriloByte Statistical Software, Ltd., Pardubice, Czech Republic). For pure coals and Type I cokes, the statistical results are shown in Table 1(a) and the same for coal blends and Type II cokes is summarized in Table 1(b).

Normality is evaluated based on a combination of skewness and kurtosis. The normal (i.e. the Gaussian) distribution exhibits skewness close to 0 and kurtosis of ca. 3. If the differences of skewness and kurtosis values from 0 and 3 are statistically significant, the distribution cannot be regarded as symmetrical. In cases where normality is rejected, the torque characteristics (i.e. the mean, standard deviation STD and variance) are replaced by robust characteristics (i.e. by the median, median standard deviation and median variance). The number of outliers for the studied characteristics (i.e. values considered as suspicious of remoteness) are listed in Table 1.

Comparing the mean values of coal and coal blend characteristics, the lower values of $b(26 \%)$, $F_{\text {max. }}(56 \%)$ and $V$ itr $(14 \%)$ and somewhat greater values of Inert $(14 \%)$ and Cat. I. (18\%) were obtained for coal blends. In case of other characteristics, the differences were lower than $10 \%$.

The standard deviations (STD) of coal blend characteristics are much lower than those of coal characteristics. Moreover, STD of Type II cokes are lower than those of Type I cokes (Table 1). Lower STD values for coal blend and Type II cokes characteristics relate to the blending principle.
Moreover, along with CRI and CSR indexes, the other two coke characteristics were determined - ash content $\mathrm{A}^{\mathrm{d}}$ (coke) ranging from 6.10 to 13.60 and volatile combustibles $\mathrm{V}^{\mathrm{d}}$ (coke) from 0.60 to $3.70 \%$. These complementary characteristics were not included in the statistical evaluation.

\subsection{FACTOR ANALYSIS}

\subsubsection{COALS (FOR TYPE I COKES)}

The factor analysis (FA) is a multidimensional statistical method based on the analysis of the mutual relationships of the variables and an assumption that these relationships are the results of a small number of underlying immeasurable factors. Thus, the purpose of FA is to reduce the number of variables and reveal the structure of relationships among them. One of the basic objectives of the factor analysis is to assess the relationship structure of the monitored variables and to determine whether they can be aggregated into groups in which the studied variables correlate together and have as little correlation as possible with other variables in other groups (factors) (Jöreskog et al., 1976; Klika et al., 2014).

FA was used for the evaluation of the experimentally determined characteristics of coals and related Type I cokes. The data used for this calculation contained 14 coal and 2 coke characteristics for 61 coals and related Type I cokes. The factor loadings calculated from 16 variables in the set of 61 coal and 61 coke (Type I) samples are presented in Table 2. The highest factor loading for each characteristic is then assigned to one of the factors F1- F4 (Table 3).

In each of the 4 factors the variables are divided into 2 groups. For example, the factor $1(\mathrm{~F} 1)$ is represented by 5 characteristics $\left(\mathrm{A}^{\mathrm{d}}, \mathrm{SI}\right.$, Vitr, Alkalis, $\mathrm{CSR}$ ) in the first positive group (the positive factor loading) and by 5 characteristics (Lipt, Inert, Cat. I., 
Table 1 Basic statistics of coal and coke characteristics, (a) for pure coals and Type I cokes, (b) for coal blends and Type II cokes.

\begin{tabular}{|c|c|c|c|c|c|c|c|c|c|c|c|c|c|c|c|c|}
\hline \multirow[t]{2}{*}{ (a) } & \multicolumn{13}{|c|}{ Coals } & \multicolumn{3}{|c|}{ I cokes } \\
\hline & $\begin{array}{l}\mathrm{A}^{\mathrm{d}} \\
(\%)\end{array}$ & $\begin{array}{l}\mathrm{V}^{\mathrm{d}} \\
(\%)\end{array}$ & $\begin{array}{c}a \\
(\%) \\
\end{array}$ & $\begin{array}{c}\mathrm{b} \\
(\%)\end{array}$ & $\begin{array}{l}\text { SI } \\
(-)\end{array}$ & $\begin{array}{c}\mathrm{F}_{\max .} \\
(\mathrm{ddpm})\end{array}$ & $\begin{array}{c}R_{r} \\
(\%)\end{array}$ & $\begin{array}{l}\text { Vitr } \\
(\%)\end{array}$ & $\begin{array}{l}\text { Lipt } \\
(\%)\end{array}$ & $\begin{array}{c}\text { Inert } \\
(\%)\end{array}$ & $\begin{array}{c}\text { Cat. I. } \\
(-)\end{array}$ & $\begin{array}{c}\text { Alk. I. } \\
(-)\end{array}$ & $\begin{array}{c}\text { Alkalis } \\
(\%)\end{array}$ & $\begin{array}{l}\mathrm{S}^{\mathrm{d}} \\
(\%)\end{array}$ & $\begin{array}{l}\text { CRI } \\
(\%)\end{array}$ & $\begin{array}{c}\text { CSR } \\
(\%) \\
\end{array}$ \\
\hline Mean & 7.27 & 24.8 & 23.8 & 49.0 & 7.30 & 540 & 1.10 & 56.6 & 6.78 & 36.6 & 0.28 & 2.14 & 0.21 & 0.54 & 35.5 & 56.6 \\
\hline Minimum & 4.70 & 16.4 & 15.0 & 6.00 & 5.00 & 3.00 & 0.84 & 37.5 & 0.5 & 15.3 & 0.15 & 1.08 & 0.074 & 0.35 & 22.7 & 36.6 \\
\hline Maximum & 11.3 & 31.3 & 33.0 & 181 & 8.50 & 9023 & 1.54 & 80.3 & 11.8 & 51.4 & 0.94 & 5.4 & 0.39 & 0.74 & 56.7 & 71.3 \\
\hline STD & 1.38 & 3.65 & 3.80 & 3.32 & 0.75 & 61.0 & 0.006 & 12.6 & 3.1 & 10.4 & 0.02 & 0.12 & 0.081 & 0.1 & 8.91 & 9.68 \\
\hline Variance & 1.89 & 13.3 & 14.5 & 11.0 & 0.56 & 3717 & 3.75 & 158 & 9.64 & 109 & $<0.001$ & 0.014 & 0.007 & 0.01 & 79.4 & 93.8 \\
\hline Skewness & 0.32 & -0.064 & 0.27 & 1.28 & -0.83 & 5.56 & 1.08 & -0.057 & -0.29 & -0.069 & 1.53 & 1.21 & 0.11 & -0.14 & 0.55 & -0.23 \\
\hline Kurtosis & 3.05 & 3.06 & 2.98 & 6.67 & 3.38 & 36.1 & 5.02 & 1.76 & 1.93 & 1.71 & 5.13 & 4.94 & 2.07 & 2.07 & 2.31 & 1.81 \\
\hline Normality & $\begin{array}{l}\text { Acc. } \\
0\end{array}$ & $\begin{array}{l}\text { Acc. } \\
4\end{array}$ & $\begin{array}{c}\text { Acc. } \\
0\end{array}$ & $\begin{array}{l}\text { Rej. } \\
1\end{array}$ & $\begin{array}{l}\text { Acc. } \\
0\end{array}$ & $\begin{array}{c}\text { Rej. } \\
2\end{array}$ & Rej. & Acc. & Acc. & Acc. & Rej. & Rej. & Acc. & Acc. & Acc. & Acc. \\
\hline
\end{tabular}

Note: ${ }^{\mathrm{d}}$ - dry basis; Rej. - rejected; Acc. - accepted; STD - standard deviation.

\begin{tabular}{|c|c|c|c|c|c|c|c|c|c|c|c|c|c|c|c|c|}
\hline \multirow[t]{2}{*}{ (b) } & \multicolumn{11}{|c|}{ Coal blends } & \multirow[b]{2}{*}{$\begin{array}{c}\text { Alk. I. } \\
(-)\end{array}$} & \multirow[b]{2}{*}{$\begin{array}{c}\text { Alkalis } \\
(\%)\end{array}$} & \multirow[b]{2}{*}{$\begin{array}{l}S^{d} \\
(\%)\end{array}$} & \multicolumn{2}{|c|}{ II cokes } \\
\hline & $\begin{array}{l}A^{d} \\
(\%)\end{array}$ & $\begin{array}{l}V^{d} \\
(\%)\end{array}$ & $\begin{array}{c}a \\
(\%)\end{array}$ & $\begin{array}{c}\mathrm{b} \\
(\%)\end{array}$ & $\begin{array}{l}\text { SI } \\
(-)\end{array}$ & $\begin{array}{c}\mathrm{F}_{\max .} \\
(\mathrm{ddpm})\end{array}$ & $\begin{array}{c}\mathrm{R}_{\mathrm{r}} \\
(\%)\end{array}$ & $\begin{array}{l}\text { Vitr } \\
(\%)\end{array}$ & $\begin{array}{l}\text { Lipt } \\
(\%)\end{array}$ & $\begin{array}{l}\text { Inert } \\
(\%)\end{array}$ & $\begin{array}{c}\text { Cat. I. } \\
(-)\end{array}$ & & & & $\begin{array}{l}\text { CRI } \\
(\%)\end{array}$ & $\begin{array}{c}\text { CSR } \\
(\%)\end{array}$ \\
\hline Mean & 7.00 & 26.0 & 24.6 & 38.7 & 7.10 & 346 & 1.02 & 49.7 & 7.40 & 42.6 & 0.34 & 2.36 & 0.19 & 0.52 & 37.3 & 56.4 \\
\hline Minimum & 6.27 & 24.1 & 20.0 & 24.0 & 6.00 & 3.00 & 1.01 & 46.7 & 5.50 & 29.9 & 0.25 & 1.96 & 0.17 & 0.45 & 31.5 & 50.7 \\
\hline Maximum & 7.87 & 27.3 & 29.0 & 69.0 & 7.50 & 201 & 1.07 & 63.8 & 9.30 & 46.8 & 0.52 & 3.80 & 0.23 & 0.58 & 42.8 & 62.2 \\
\hline STD & 0.36 & 0.68 & 2.18 & 9.26 & 0.39 & 37.5 & 0.004 & 0.41 & 0.88 & 0.38 & 0.007 & 0.056 & 0.017 & 0.034 & 2.58 & 3.09 \\
\hline Variance & 0.13 & 0.46 & 4.76 & 85.8 & 0.15 & 1406 & $<0.001$ & 0.17 & 0.77 & 0.15 & $<0.001$ & 0.003 & $<0.001$ & 0.001 & 6.67 & 9.57 \\
\hline Skewness & 0.64 & -0.62 & 0.011 & 0.87 & -0.71 & 1.19 & 1.14 & 2.96 & -0.47 & -2.93 & 1.22 & 1.73 & 0.44 & -0.22 & -0.35 & 0.29 \\
\hline Kurtosis & 3.63 & 3.32 & 2.68 & 4.39 & 3.02 & 4.00 & 3.63 & 11.76 & 2.54 & 12.18 & 4.52 & 5.99 & 2.32 & 2.61 & 2.71 & 2.44 \\
\hline $\begin{array}{l}\text { Normality } \\
\text { Outliers }\end{array}$ & $\begin{array}{l}\text { Acc. } \\
0\end{array}$ & $\begin{array}{c}\text { Acc. } \\
0\end{array}$ & $\begin{array}{l}\text { Acc. } \\
0\end{array}$ & $\begin{array}{l}\text { Acc. } \\
0\end{array}$ & $\begin{array}{l}\text { Acc. } \\
0\end{array}$ & $\begin{array}{l}\text { Rej. } \\
0\end{array}$ & $\begin{array}{l}\text { Rej. } \\
0\end{array}$ & $\begin{array}{l}\text { Rej. } \\
2\end{array}$ & $\begin{array}{l}\text { Acc. } \\
0\end{array}$ & $\begin{array}{l}\text { Rej. } \\
2\end{array}$ & $\begin{array}{l}\text { Rej. } \\
3\end{array}$ & $\begin{array}{l}\text { Rej. } \\
2\end{array}$ & $\begin{array}{l}\text { Acc. } \\
0\end{array}$ & $\begin{array}{l}\text { Acc. } \\
0\end{array}$ & $\begin{array}{l}\text { Acc. } \\
0\end{array}$ & $\begin{array}{l}\text { Acc. } \\
0\end{array}$ \\
\hline
\end{tabular}

Note: ${ }^{\mathrm{d}}$ - dry basis; Rej. - rejected; Acc. - accepted; STD - standard deviation. 
Table 2 The factor loadings for coals and their cokes (Type I) after Varimax rotation.

\begin{tabular}{lrrrr}
\hline Characteristic & Factor 1 & Factor 2 & Factor 3 & Factor 4 \\
\hline $\mathrm{A}^{\mathrm{d}}$ & $\mathbf{0 . 6 8 6}$ & 0.170 & -0.158 & -0.410 \\
$\mathrm{~V}^{\mathrm{d}}$ & -0.030 & $\mathbf{0 . 9 3 0}$ & 0.161 & 0.084 \\
$\mathrm{a}$ & 0.034 & $\mathbf{0 . 8 5 3}$ & 0.011 & -0.014 \\
$\mathrm{~b}$ & 0.154 & -0.169 & $\mathbf{0 . 8 9 9}$ & -0.223 \\
$\mathrm{SI}$ & $\mathbf{0 . 6 4 7}$ & -0.301 & 0.151 & -0.244 \\
$\mathrm{~F}_{\text {max. }}$ & 0.111 & 0.221 & $\mathbf{0 . 8 4 5}$ & -0.043 \\
$\mathrm{R}_{\mathrm{r}}$ & -0.075 & $\mathbf{- 0 . 9 3 3}$ & 0.030 & -0.148 \\
Vitr & $\mathbf{0 . 9 1 9}$ & -0.045 & 0.239 & -0.112 \\
Lipt & $\mathbf{- 0 . 7 4 4}$ & 0.519 & -0.158 & 0.247 \\
Inert & $\mathbf{- 0 . 8 7 4}$ & -0.156 & -0.325 & 0.122 \\
Cat. I. & $\mathbf{- 0 . 8 7 1}$ & 0.130 & -0.068 & 0.430 \\
Alk. I. & $\mathbf{- . 8 6 9}$ & 0.260 & -0.226 & 0.224 \\
Alkalis & $\mathbf{0 . 8 1 5}$ & 0.248 & -0.134 & -0.314 \\
S $^{\mathrm{d}}$ & 0.436 & 0.265 & 0.353 & $-\mathbf{0 . 5 3 7}$ \\
CRI & $\mathbf{- 0 . 7 1 7}$ & 0.188 & -0.107 & 0.615 \\
CSR & $\mathbf{0 . 6 0 0}$ & -0.595 & 0.125 & -0.445 \\
\hline
\end{tabular}

Table 3 The results of the factor analysis of coal and related Type I coke characteristics.

\begin{tabular}{c|c|c|c}
\hline Factor & Group (+) & Group (-) & R >0.6 \\
\hline F1 & A $^{\mathrm{d}}$; SI; Vitr; Alkalis; CSR & Lipt; Inert; Cat. I.; Alk. I.; CRI & 24 \\
F2 & V $^{\text {d }}$ a & $\mathrm{R}_{\mathrm{r}}$ & 3 \\
F3 & b; F & - & 1 \\
F4 & - & $\mathrm{S}^{\mathrm{d}}$ & - \\
\hline \multicolumn{2}{c}{ Total number } & 4 \\
\hline \multicolumn{2}{c}{ R among F1 - F4 factors } \\
\hline
\end{tabular}

Note: $\mathrm{R}$ - correlation coefficients

Table 4 The highest correlation coefficients (R) between characteristics contained in factor F1.

\begin{tabular}{lrlrlr}
\hline Characteristics & \multicolumn{1}{c}{$\mathrm{R}$} & Characteristics & $\mathrm{R}$ & Characteristics & $\mathrm{R}$ \\
\hline Vitr - Inert & -0.935 & Alk. I. - CRI & 0.752 & Vitr - Alkalis & 0.672 \\
Cat. I. - Alk. I. & 0.918 & Vitr - CRI & -0.748 & Lipt - Inert & 0.668 \\
Lipt - CSR & -0.904 & Alkalis - CRI & -0.712 & Vitr - CSR & 0.659 \\
A $^{\mathrm{d}}$ - Alkalis & 0.891 & Cat. I. - CSR & -0.710 & SI - CRI & -0.658 \\
CRI - CSR & -0.875 & Inert - CRI & 0.696 & SI - Lipt & -0.646 \\
Cat. I. - CRI & 0.848 & Alk. I. - CSR & -0.694 & SI - CSR & 0.640 \\
Lipt - CRI & 0.802 & Inert - Alkalis & -0.691 & SI - Vitr & 0.639 \\
Vitr - Lipt & -0.779 & A $^{\mathrm{d}}-$ CRI & -0.676 & A $^{\mathrm{d}}-$ Cat. I. & -0.631 \\
\hline
\end{tabular}

Alk. I., CRI) in the second negative group (the negative factor loading). The correlation coefficients among characteristics in the first (+) group of F1 are within the range from 0.371 to 0.917 and those of the second (-) group from 0.390 to 0.847 . The correlation coefficients among any variable (characteristic) of the first and the second group vary from -0.328 to -0.935 . The factor 1 contains 24 total correlation coefficients ranging from $|0.631|$ to $|0.935|$ (Table 4).

Next factors F2, F3 and F4 can be explained analogously, but they contain much lower number of characteristics and correlation coefficients inside each factor. The total number of the strongest correlation coefficients $n(R)=32$, where 3 of them belong to F2 and 1 to F3 factors. Remaining 4 strongest correlation coefficients belong to characteristics included between 2 different factors (Table 3). Assignment of coal characteristics by factor analysis is illustrated in Figure 2.

In the first factor $F 1$, the sum of all 3 coal macerals equals to $100 \%$ (Fig. 3A); therefore, the information on the content of one of these macerals is redundant. Furthermore, alkali index (Fig. 3B) includes catalytic index (Eq. 1) and also the correlation coefficients between Vitr - Inert and Cat. I. - Alk. I. are high; for this reason, one of these characteristics can be eliminated from regression equations as well. Therefore, for further consideration (regression analysis) the number of coal characteristics in F1 factor can be reduced to 6 . 


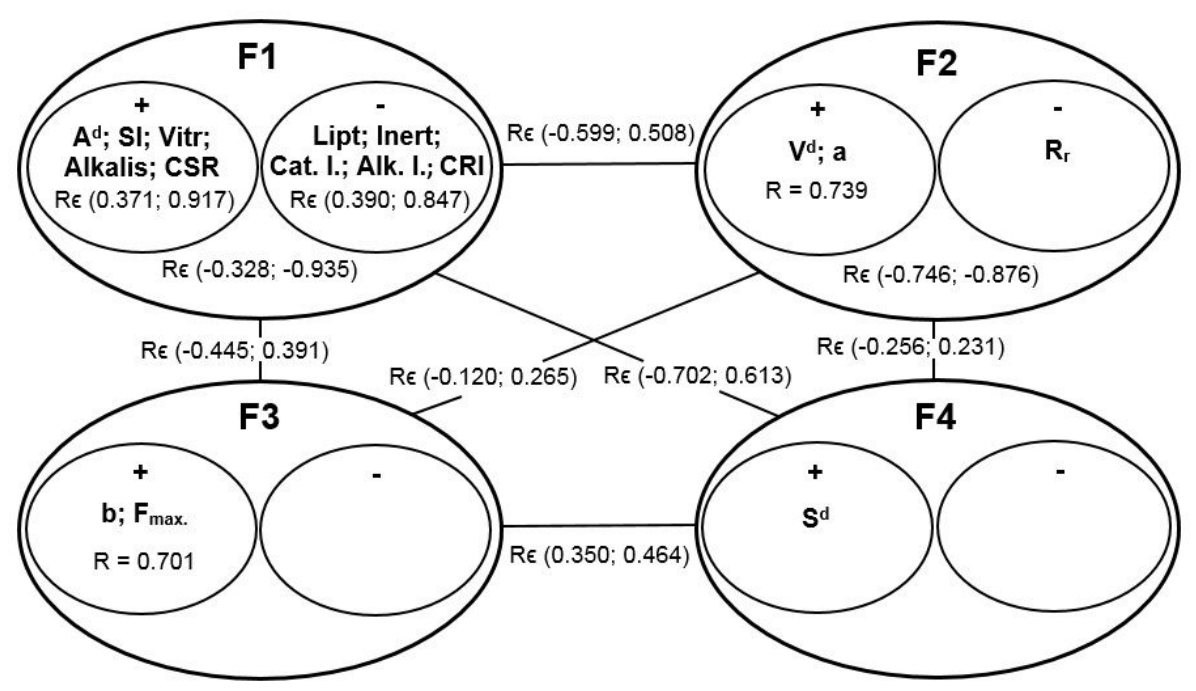

Fig. 2 Scheme of calculated factors F1, F2, F3 and F4 with their mutual correlation coefficients among coal and Type I coke characteristics.

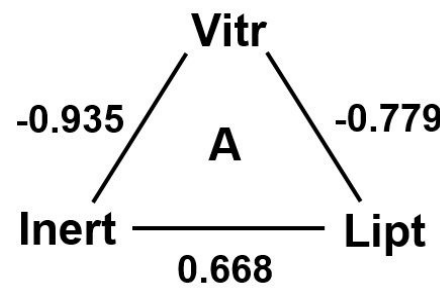

Fig. 3 Correlation coefficients among coal macerals (A) and characteristics containing alkali elements (B).

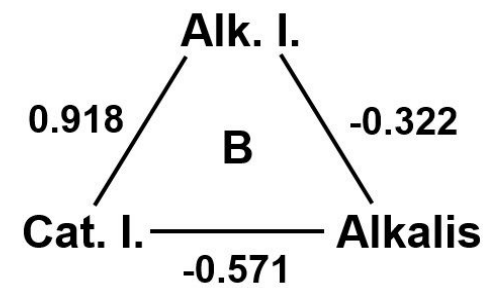

\subsubsection{COAL BLENDS (FOR TYPE II COKES)}

FA was also used for the evaluation of 14 experimentally determined characteristics of 36 coal blends and related CRI and CSR indexes of 36 cokes (Type II). From these data the factor loadings were calculated and the highest factor loading for each characteristic assigned to one of the factors F1- F7 (Table 5).

In contrast to total numbers of factors $n(F)=4$ calculated for previous 61 coals and related cokes (Type I) (section 3.2.1), for 36 coal blends and Type II cokes data, $\mathrm{n}(\mathrm{F})=7$ factors were calculated. The characteristics of coal blends and Type II cokes are distributed within 7 factors indicating that there are poor correlations among them (Table 6). The total number of the correlation coefficients $n(R)$ being higher than $|0.60|$ is much lower (4) than that obtained for pure coals and Type I cokes data (32). They are Vitr - Inert (-0.970), Cat. I. - Alk. I. (0.957), CRI CSR (-0.918) and $\mathrm{V}^{\mathrm{d}}-\mathrm{S}^{\mathrm{d}}(0.628)$. Moreover, the correlation coefficients of coal blend characteristics with CRI and/or with CSR indexes are even lower than $\mathrm{R}=0.360$. This is in striking contrast to 14 high correlation coefficients with $\mathrm{R}>|0.60|$ between CRI (8) and/or CSR (6) with coal characteristics presented before in section 3.2.1 (Table 4). Also, the total number of factors $n(F)$ and the total number of the correlation coefficients $n(R)>|0.60|$ for coals and cokes (Type I) and for coal blends and cokes (Type II) are quite different (Fig. 4).

In this study, correlation coefficients between studied characteristics calculated for the coal blends exhibited significantly lower values than those calculated for pure coking coals. It can be attributed to the fact that coal blends were prepared by blending of the coking coal samples thereby averaging their characteristics; i.e., variances of their characteristics are typically much lower than those of pure coking coals (Table 1). Moreover, coal blending probably resulted in low correlation coefficients calculated for the relationships of CRI and CSR (Type II) with the characteristics of coal blends.

\subsection{REGRESSION ANALYSIS}

\subsubsection{TYPE I COKES (FROM COALS)}

For the prediction of CRI and CSR, the following regression equations (4 and 5) based on coal characteristics have been proposed. They are:

$C R I_{j}=\sum_{i=1}^{n} k_{i}^{*} \cdot P_{i, j}+$ const

$C S R_{j}=\sum_{i=1}^{n} k_{i}^{* *} \cdot P_{i, j}+$ const

where $P_{i, j}$ is the $i$-th characteristic of the $j$-th coal sample; $k_{i}^{*}$ and/or $k_{i}^{* *}$ are the $i$-th coefficients related to $P_{i, j}$; const is constant; $C R I_{j}$ and/or $C S R_{j}$ are indexes 
Table 5 The factor loadings for coal blends and their cokes (Type II) after Varimax rotation.

\begin{tabular}{crrrrrrr}
\hline Characteristic & Factor 1 & \multicolumn{1}{c}{ Factor 2 } & \multicolumn{1}{c}{ Factor 3 } & \multicolumn{1}{c}{ Factor 4 } & Factor 5 & Factor 6 & Factor 7 \\
\hline $\mathrm{A}^{\mathrm{d}}$ & 0.020 & $\mathbf{- 0 . 7 7 7}$ & -0.026 & 0.061 & 0.151 & 0.012 & 0.115 \\
$\mathrm{~V}^{\mathrm{d}}$ & -0.095 & 0.075 & 0.061 & -0.093 & $\mathbf{- 0 . 9 1 7}$ & 0.209 & 0.032 \\
$\mathrm{a}$ & 0.233 & -0.178 & -0.091 & 0.026 & 0.080 & $\mathbf{0 . 7 9 6}$ & -0.116 \\
$\mathrm{~b}$ & -0.194 & $\mathbf{0 . 7 1 8}$ & 0.094 & -0.056 & 0.014 & 0.487 & 0.228 \\
$\mathrm{SI}$ & 0.049 & 0.239 & -0.074 & -0.114 & 0.002 & 0.109 & $\mathbf{0 . 7 6 2}$ \\
$\mathrm{F}_{\text {max. }}$ & -0.189 & 0.467 & 0.043 & -0.051 & -0.273 & $\mathbf{0 . 7 0 4}$ & 0.144 \\
$\mathrm{R}_{\mathrm{r}}$ & -0.039 & 0.058 & -0.194 & 0.090 & 0.441 & 0.202 & $\mathbf{- 0 . 6 3 2}$ \\
Vitr & 0.088 & -0.009 & $\mathbf{0 . 9 7 6}$ & 0.107 & -0.109 & -0.018 & -0.091 \\
Lipt & -0.251 & -0.175 & -0.386 & -0.297 & 0.421 & -0.056 & $\mathbf{0 . 5 4 9}$ \\
Inert & -0.027 & 0.061 & $\mathbf{- 0 . 9 8 5}$ & -0.035 & 0.001 & 0.036 & -0.056 \\
Cat. I. & -0.150 & 0.223 & -0.071 & $\mathbf{- 0 . 9 5 2}$ & -0.005 & 0.010 & 0.103 \\
Alk. I. & -0.137 & 0.003 & -0.083 & $\mathbf{- 0 . 9 6 4}$ & 0.038 & 0.004 & 0.137 \\
Alkalis & -0.111 & $\mathbf{- 0 . 8 5 2}$ & 0.169 & 0.115 & 0.036 & 0.134 & -0.211 \\
S & 0.248 & 0.144 & 0.016 & 0.145 & $\mathbf{- 0 . 8 2 3}$ & -0.142 & 0.058 \\
CRI & $\mathbf{- 0 . 9 5 2}$ & 0.018 & -0.033 & -0.119 & 0.141 & -0.026 & -0.063 \\
CSR & $\mathbf{0 . 9 4 9}$ & -0.020 & 0.098 & 0.159 & 0.006 & 0.058 & -0.045 \\
\hline
\end{tabular}

Table 6 The results of the factor analysis of coal blends and related Type II coke characteristics.

\begin{tabular}{c|c|c|c}
\hline Factor & Group $(+)$ & Group $(-)$ & $\mathrm{R}>0.6$ \\
\hline F1 & CSR & CRI & 1 \\
F2 & b & A ; Alkalis & 1 \\
F3 & Vitr & Inert & 1 \\
F4 & - & Cat. I.; Alk. I. & 1 \\
F5 & - & V $^{\mathrm{d}} ; \mathrm{S}^{\mathrm{d}}$ & - \\
F6 & - & - \\
F7 & a; F Fax. & $\mathrm{R}_{\mathrm{r}}$ & - \\
\hline \multicolumn{3}{c}{ SI; Lipt } \\
\hline
\end{tabular}

Note: $\mathrm{R}$ - correlation coefficients

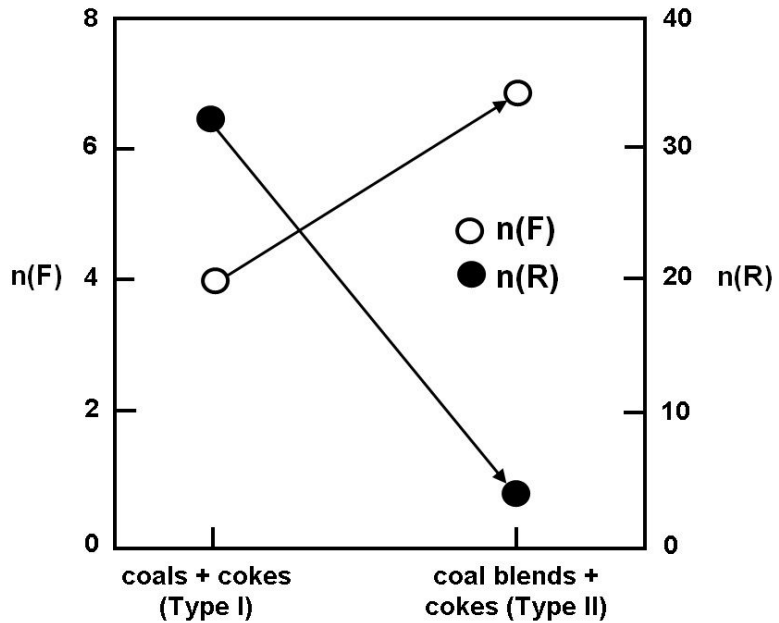

Fig. 4 Trends of the total number of factors $n(F)$ and total number of the correlation coefficients $\mathrm{n}(\mathrm{R})>|0.60|$ between coals and cokes (Type I) and coal blends and cokes (Type II). of the $j$-th coke sample and $n$ is the number of coal characteristics.

The results of the FA allow distinguish importance of the individual coal characteristics for the calculation of CRI and CSR prediction. For example, the $\mathrm{S}^{\mathrm{d}}$ characteristic included in the factor $\mathrm{F} 4$ (Fig. 2) exhibited rather poor correlations with other characteristics; therefore, it was omitted from further regression calculation.

For the evaluation of the $k_{i}^{*}$ and/or $k_{i}^{* *}$ coefficients and constants const in Eqs. 4 and 5, the $P_{i, j}$ experimental characteristics of coals and experimentally determined $C R I_{j} / C S R_{j}$ values of Type I cokes were used. These coefficients as well as constants (const) were calculated using regression analysis and they are given for different variants in Table 7. For the variant 1 , the $k_{i}^{*}$ and/or $k_{i}^{* *}$ coefficients were calculated for 13 coal characteristics (F1, F2 and F3 factors) and for variant 2, they were calculated for 8 coal characteristics (factor F1). In the variant 3, the coal characteristics in F1 were reduced by Vitr and Alk. I. and in variant 4 only the Lipt and Inert were used. However, the reduction of characteristics in variants 3 and 4 in Eqs. 4 and 5 is 

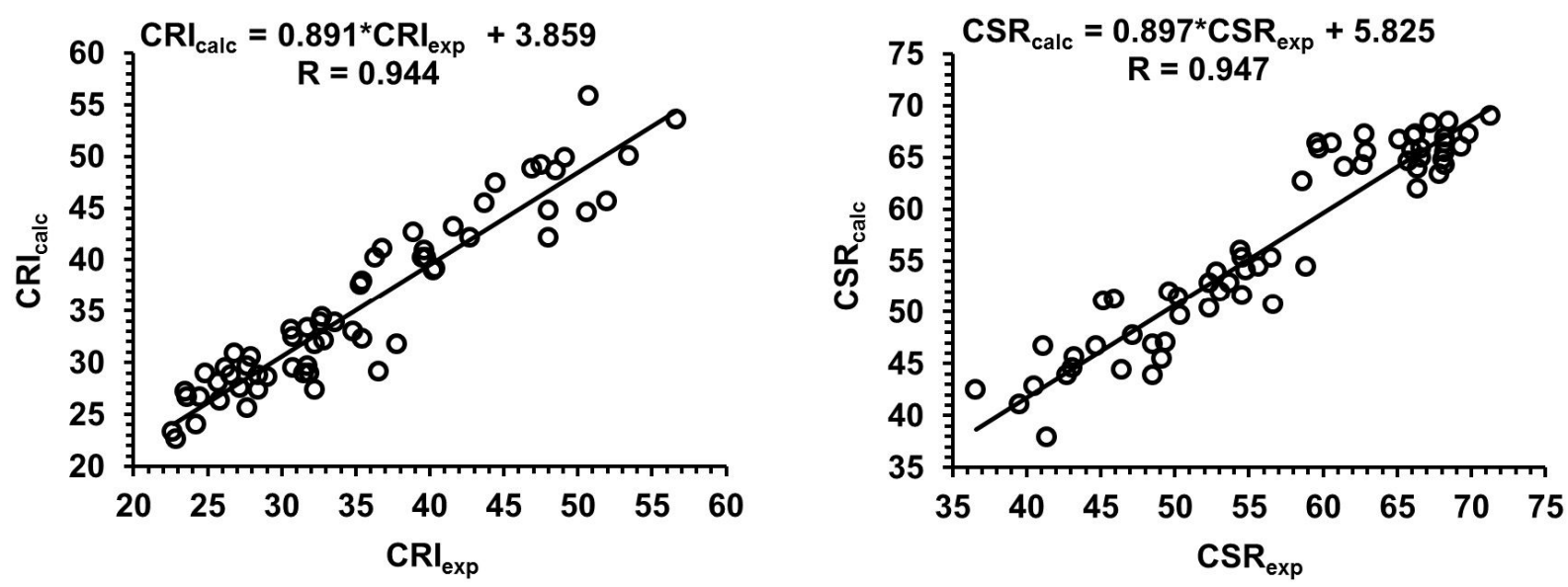

Fig. 5 Plots between predicted (calc) and experimentally (exp) determined Type I coke indexes. Left - CRI; right $-\mathrm{CSR}$.

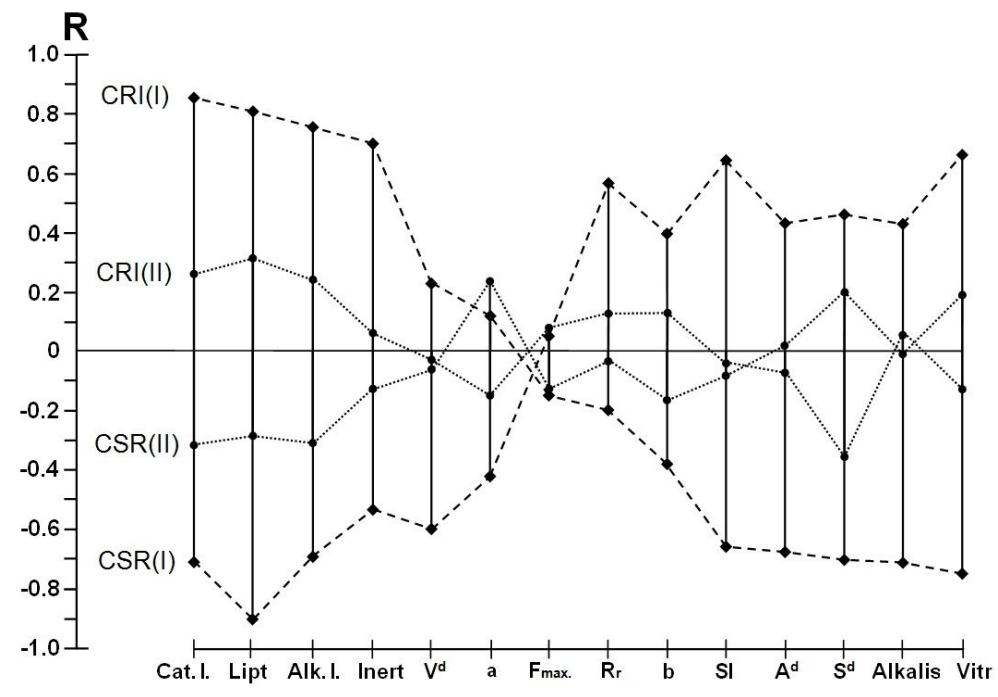

Fig. 6 Zig-zag plots of the correlation coefficients (R) and pure coal (I) and/or coal blend (II) characteristics. CRI(I) and CSR(I) zig-zag plots predicted from pure coal (I) characteristics (sec. 3.3.1.); CRI(II) and CSR(II) zig-zag plots predicted from coal blend (II) characteristics (sec. 3.3.2.).

supported by adding new constants (Table 7). Moreover, $k_{i}^{*}$ and $k_{i}^{* *}$ coefficients and constants const were also calculated from regression equations (Eqs. 4 and 5) for each of 14 single $P_{i, j}$ coal characteristics $\left(\mathrm{A}^{\mathrm{d}}, \mathrm{V}^{\mathrm{d}}, \mathrm{a}, \mathrm{b}, \mathrm{SI}, \mathrm{F}_{\text {max. }}, \mathrm{R}_{\mathrm{r}}\right.$, Vitr, Lipt, Inert, Cat. I., Alk. I., Alkalis, $\mathrm{S}^{\mathrm{d}}$ ) and experimentally determined $C R I_{j} / C S R_{j}$ values of I cokes. These data are not presented here.

Conversely, for all calculated $k_{i}^{*}$ and $k_{i}^{* *}$ coefficients, const and the relevant $P_{i, j}$ coal characteristics, the CRI and CSR indexes were predicted (Eqs. 4 and 5). These predicted data were compared with experimentally determined CRI/CSR and correlation coefficients $\mathrm{R}$ were calculated. The correlations are very high for variants 1-4 (Table 7) but they drop when the coal characteristics from F2 or F3 factors for CRI/CSR prediction are used (not shown). The best regression functions between predicted $\mathrm{CRI}_{\text {calc }}$ and experimentally determined
$\mathrm{CRI}_{\exp }(\mathrm{R}=0.944)$ as well as predicted $\mathrm{CSR}_{\text {calc }}$ and experimentally determined $\mathrm{CSR}_{\exp }(\mathrm{R}=0.947)$ are plotted in Figure 5.

CRI and CSR of Type I cokes were separately predicted using pure coal characteristics. After that, they were compared with relevant experimentally determined CRI and CSR indexes, their correlation coefficients $\mathrm{R}$ calculated and plotted versus these coal characteristics (Fig. 6). These curves confirm a negative correlation between both Type I coke indexes. The differences in $\mathrm{R}$ between both zig-zag curves are more significant for Cat. I., Alk. I., Lipt and Inert as well as for Vitr, SI, Alkalis and $\mathrm{A}^{\mathrm{d}}$ characteristics of $\mathrm{F} 1$ factor, while the differences in $\mathrm{R}$ between CRI(I) and CSR(I) zig-zag curves for $\mathrm{V}^{\mathrm{d}}$, a, $F_{\text {max., }} b, R_{r}$ characteristics of $F 2$ and $F 3$ factors are less significant (Fig. 6). These results also show the dominant role of coal characteristics included within factor F1. 
Table 7 Calculated $k_{i}^{*}, k_{i}^{* *}$ coefficients, constants const and correlation coefficients R for the prediction of CRI and CSR of Type I cokes.

\begin{tabular}{|c|c|c|c|c|c|c|c|c|c|c|c|c|c|c|c|c|}
\hline Variants & $\begin{array}{c}\text { Coke } \\
\text { indexes }\end{array}$ & $\begin{array}{c}1 \\
A^{d}\end{array}$ & $\begin{array}{c}2 \\
\mathrm{~V}^{\mathrm{d}}\end{array}$ & $\begin{array}{l}3 \\
\mathrm{a}\end{array}$ & $\begin{array}{l}4 \\
\mathrm{~b}\end{array}$ & $\begin{array}{c}5 \\
\text { SI }\end{array}$ & $\begin{array}{c}6 \\
F_{\max }\end{array}$ & $\begin{array}{c}7 \\
\mathrm{R}_{\mathrm{r}}\end{array}$ & $\begin{array}{c}8 \\
\text { Vitr }\end{array}$ & $\begin{array}{c}9 \\
\text { Lipt }\end{array}$ & $\begin{array}{c}10 \\
\text { Inert }\end{array}$ & $\begin{array}{c}11 \\
\text { Cat. I. }\end{array}$ & $\begin{array}{c}12 \\
\text { Alk. I. }\end{array}$ & $\begin{array}{c}13 \\
\text { Alkalis }\end{array}$ & const & $\mathrm{R}$ \\
\hline \multirow{2}{*}{1} & CRI & -0.533 & -0.119 & 0.138 & -0.016 & -0.792 & $<0.001$ & 7.311 & 0.146 & 1.603 & 0.257 & 20.19 & 0.331 & 6.384 & & 0.944 \\
\hline & CSR & 0.398 & -0.945 & -0.201 & 0.010 & 0.957 & $<0.001$ & -30.59 & 1.318 & -0.937 & 1.391 & -6.014 & -2.973 & -12.11 & & 0.947 \\
\hline \multirow{2}{*}{2} & CRI & -0.592 & & & & -0.957 & & & 0.254 & 1.302 & 0.392 & 19.29 & 0.753 & 3.533 & & 0.937 \\
\hline & CSR & 0.403 & & & & 1.089 & & & 0.656 & -1.487 & 0.804 & -13.62 & -1.778 & -8.846 & & 0.930 \\
\hline \multirow{2}{*}{3} & CRI & -0.408 & & & & -0.953 & & & & 1.067 & 0.139 & 23.44 & & 3.941 & 24.13 & 0.937 \\
\hline & CSR & -0.031 & & & & 1.080 & & & & -2.191 & 0.144 & -23.45 & & -9.812 & 68.69 & 0.929 \\
\hline \multirow{2}{*}{4} & CRI & & & & & & & & & 1.735 & 0.303 & & & & 12.60 & 0.867 \\
\hline & CSR & & & & & & & & & -2.802 & 0.033 & & & & 74.41 & 0.877 \\
\hline
\end{tabular}

Note: columns 1-13 $-k_{i}^{*}$ and $k_{i}^{* *}$ coefficients for 1-13 coal characteristics; const - calculated constant; R - correlation coefficient between predicted and experimental CRI and/or CSR.

Table 8 Calculated $k_{i}^{*}, k_{i}^{* *}$ coefficients, constants const and correlation coefficients $\mathrm{R}$ for the prediction of CRI and CSR of Type II cokes.

\begin{tabular}{|c|c|c|c|c|c|c|c|c|c|c|c|c|c|c|c|c|c|}
\hline Variants & $\begin{array}{c}\text { Coke } \\
\text { indexes }\end{array}$ & $\begin{array}{c}1 \\
A^{d} \\
\end{array}$ & $\begin{array}{c}2 \\
\mathrm{~V}^{\mathrm{d}} \\
\end{array}$ & $\begin{array}{l}3 \\
\mathrm{a}\end{array}$ & $\begin{array}{l}4 \\
\mathrm{~b}\end{array}$ & $\begin{array}{c}5 \\
\text { SI } \\
\end{array}$ & $\begin{array}{c}6 \\
F_{\max } \\
\end{array}$ & $\begin{array}{c}7 \\
\mathrm{R}_{\mathrm{r}} \\
\end{array}$ & $\begin{array}{c}8 \\
\text { Vitr }\end{array}$ & $\begin{array}{c}9 \\
\text { Lipt }\end{array}$ & $\begin{array}{c}10 \\
\text { Inert }\end{array}$ & $\begin{array}{c}11 \\
\text { Cat. I. }\end{array}$ & $\begin{array}{c}12 \\
\text { Alk. I. }\end{array}$ & $\begin{array}{c}13 \\
\text { Alkalis }\end{array}$ & $\begin{array}{l}14 \\
S^{d} \\
\end{array}$ & const & $\mathrm{R}$ \\
\hline \multirow{2}{*}{1} & CRI & 5.666 & 1.988 & -0.373 & 0.039 & 0.303 & -0.002 & 60.25 & -1.000 & -0.210 & -1.036 & 142.7 & -19.74 & 19.42 & -36.92 & & 0.616 \\
\hline & CSR & -20.95 & -2.633 & 0.543 & -0.104 & -1.086 & 0.006 & -47.31 & 3.114 & 2.888 & 2.982 & -440.2 & 60.69 & -16.97 & 40.13 & & 0.642 \\
\hline \multirow{2}{*}{2} & CRI & -1.318 & 1.173 & -0.355 & 0.026 & -0.115 & 0.003 & 30.83 & & 0.665 & 0.018 & & 0.416 & 26.43 & -33.51 & & 0.591 \\
\hline & CSR & 0.602 & -0.082 & 0.487 & -0.066 & 0.223 & -0.002 & 45.20 & & 0.174 & -0.190 & & -1.494 & -38.70 & 29.55 & & 0.458 \\
\hline \multirow{2}{*}{3} & CRI & -1.233 & 1.779 & -0.365 & 0.025 & 0.187 & $<0.001$ & 58.15 & & 0.919 & -0.050 & & 0.214 & 24.93 & -34.69 & -45.06 & 0.605 \\
\hline & CSR & 0.333 & -1.989 & 0.519 & -0.061 & -0.729 & 0.001 & -40.85 & & -0.625 & -0.089 & & -0.860 & -33.99 & 33.28 & 142.0 & 0.568 \\
\hline
\end{tabular}

Note: columns 1-14 $-k_{i}^{*}$ and $k_{i}^{* *}$ coefficients for 1-14 coal characteristics; const - calculated constant; R - correlation coefficient between predicted and experimental CRI and/or CSR. 

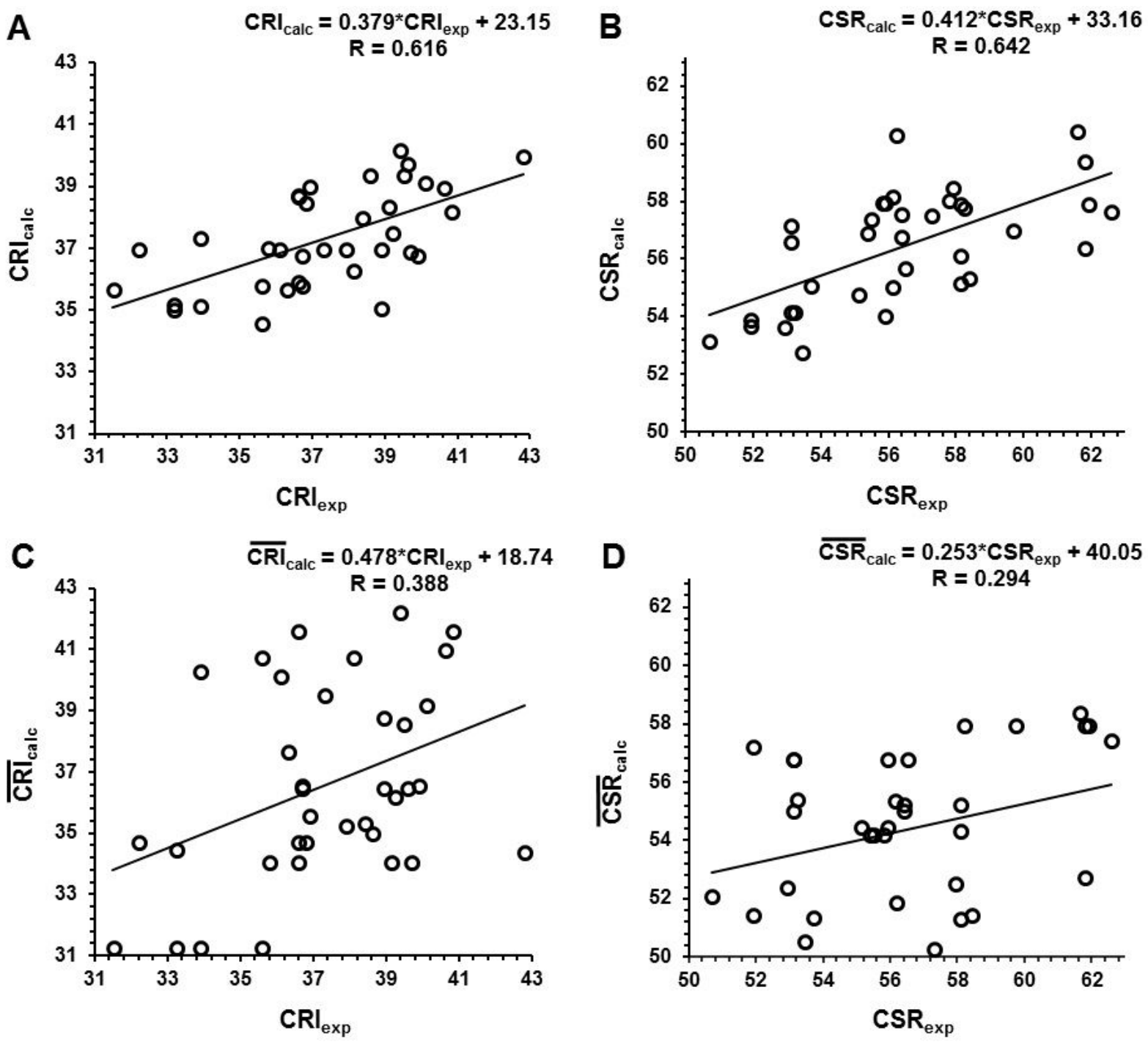

Fig. 7 Plots between calculated (calc) and experimentally (exp) determined Type II coke indexes. A - CRI, B CSR, (both predicted in sec. 3.3.2.); $\mathrm{C}-\overline{C R I}, \mathrm{D}-\overline{C S R}$, (both calculated as weighted means in sec. 3.4.).

\subsubsection{TYPE II COKES (FROM COAL BLENDS)}

Similarly as in section 3.3.1., the $k_{i}^{*}$ and/or $k_{i}^{* *}$ coefficients and constants const of linear regression (Eqs. 4 and 5) were evaluated using $P_{i, j}$ experimental characteristics of coal blends and experimentally determined $C R I_{j} / C S R_{j}$ of Type II cokes. For variant 1 , 4 coal blend characteristics (factors F1-F7) were used. Then, for variant 2, 12 coal blend characteristics (reduced from factors F1-F7 by Vitr and Cat. I.) and for variant 3 , the above 12 coal blend characteristics were used and added by constant const (Table 8 ).

Analogously to section 3.1.1., CRI and CSR indexes were predicted (Eqs. 4 and 5) and compared with experimentally determined CRI/CSR. In contrast to coals (sec. 3.3.1.), the calculated correlation coefficients $\mathrm{R}$ are lower.

In variants $1-3$, the correlation coefficients $R$ range from 0.591 to 0.616 for CRI and from 0.458 to 0.642 for CSR, respectively (Table 8 ). As expected, the correlation coefficients also drop with the decreasing number of coal blend characteristics (not shown). The best regression functions between predicted $\mathrm{CRI}_{\text {calc }}$ and experimentally determined $\mathrm{CRI}_{\text {exp }}$ (Fig. 7A) as well as between predicted $\mathrm{CSR}_{\text {calc }}$ and experimentally determined $\mathrm{CSR}_{\exp }$ (Fig. 7B) show lower correlation coefficients then those for Type I cokes (Table 7).

The correlation coefficients $\mathrm{R}$ plotted in the zigzag curves (Fig. 6) CRI(II) and CSR(II) are also much lower comparing with CRI(I) and CSR(I).

\subsection{WEIGHTED MEANS}

Except CRI and CSR prediction of Type II cokes based on regression Eqs. 4 and 5, the next prediction was calculated as weighted means of $\overline{C R I}$ and $\overline{C S R}$ by Eq. 6.

$\overline{P_{i, j}}=\frac{\sum_{m} P_{i, j, m} \cdot w_{m}}{100}$

where $\overline{P_{i, j}}$ is the weighted mean of the $i$-th Type II coke characteristic $\left(\overline{C R I}_{\mathrm{j}}\right.$ and $\left.\overline{C S R}_{\mathrm{j}}\right)$ of the $j$-th Type 
II coke sample; $P_{i, j, m}-$ is the $i$-th coke index $\left(C R I_{j}\right.$ or $C S R_{j}$ ) of the $m$-th sample of Type I coke used for the calculation of $\overline{P_{i, j}}$ characteristic of the $j$-th sample of Type II cokes; $w_{m}$ - percentages of the $m$-th sample of Type I cokes used for the calculation of the $\overline{P_{i, j}}$.

While the prediction of CRI and CSR indexes for Type I cokes is very good (Fig. 5), the prediction of Type II cokes carbonized from coal blends is poorer (Figs. 7A and 7B). This is due to lower correlation coefficients and also due to the slopes of both regression curves that are far from 1.00. The results of $\overline{C R I} / \overline{C S R}$ prediction of Type II cokes calculated as weighted means were also compared with experimentally determined CRI/CSR indexes but this comparison shows the poorest results (Figs. 7C and 7D).

\section{CONCLUSION}

A combination of the factor (FA) and regression analyses (RA) was used to predict CRI and CSR indexes of Type I cokes (prepared from pure coal samples) and Type II cokes (prepared from coal blends) in a pilot coke oven. Coals and coal blends were characterized by 14 coal characteristics $\left(\mathrm{A}^{\mathrm{d}}, \mathrm{V}^{\mathrm{d}}\right.$, contraction a and dilation $b, S I, F_{\text {max. }}, R_{r}$, Vitr, Lipt, Inert, Cat. I., Alk. I., Alkalis, $\mathrm{S}^{\mathrm{d}}$ ) and cokes were characterized by CRI and CSR indexes.

FA distributed 16 characteristics of coals and Type I cokes into 4 factors containing 32 correlation coefficients with $\mathrm{R}>|0.60|$ while in coal blends and

Type II cokes data, 7 factors and 4 correlation coefficients with $\mathrm{R}>|0.60|$ were calculated. The CRI and CSR of I and II cokes were predicted by RA based on the selected coal and/or coal blend characteristics in respect to the results of FA.

For the prediction of CRI and CSR of I cokes, the best regression equations were based on the coal characteristics presented in factor $\mathrm{F} 1\left(\mathrm{~A}^{\mathrm{d}}\right.$, SI, Cat. I., Alk. I., Alkalis, Vitr, Inert, Lipt), that contained the highest number of coal characteristics with the highest correlation coefficients (e.g. R varied from 0.930 to 0.947 , variants 1 and 2). The good prediction (high $\mathrm{R}$ between predicted and experimentally calculated CRI/CSR) was even obtained using regression based only on one coal characteristic. For example, the highest correlation coefficients R for CRI and/or CSR were obtained for the relationship with: Lipt $(0.802 /-$ 0.904), Alk. I. (0.751/-0.694) and Vitr (-0.748/0.659), respectively.

In contrast, the prediction of CRI and CSR of Type II cokes is poor due to very low correlation coefficients $\mathrm{R}$ between predicted and experimentally calculated CRI/CSR values. The best regression equations were based on the 14 coal characteristics presented in all 7 factors (variant 1, Table 8). The highest 4 correlation coefficients $\mathrm{R}$ for this prediction varied from 0.628 to 0.970 . In addition to them, among all coal blend and Type II coke characteristics, other the highest correlation coefficients between $\mathrm{CRI} / \mathrm{CSR}$ and any of the coal blend characteristic were: CRI - Lipt (0.309), CRI - S $(-0.356)$, CSR Cat. I. (-0.315) and CSR - Alk. I. (-0.309). Very good CRI/CSR predictions cannot be obtained due to low correlation coefficients.

A combination of the factor (FA) and regression analyses (RA) can be a good tool for CRI/CSR predictions calculated from coal blend characteristics. Anyway, our results showed that the more coal and/or coal blend characteristics are used, the better CRI/CSR predictions for Type I and/or II cokes are found.

However, in case of coal blends and Type II cokes, using numerous characteristics was not fully successful for a very good prediction of CRI/CSR indexes ( $\mathrm{R}=0.616$ for $\mathrm{CRI}, \mathrm{R}=0.642$ for $\mathrm{CSR}$ ). In any case, this prediction was still better than that one based on assumption of their CRI/CSR values calculated as weighted means $(\mathrm{R}=0.388$ for CRI, $\mathrm{R}=0.294$ for CSR). This paper showed that prediction of CRI/CSR of cokes (Type II) carbonized from coal blends mixed from coals of the Upper Silesian Coal Basin cannot be successfully calculated neither from various regression equations nor by weighted means of cokes (Type I).

\section{ACKNOWLEDGEMENTS}

The authors are grateful to Ministry of Education, Youth and Sports of the Czech Republic for the financial support (project no. LO1203 "Regional Materials Science and Technology CentreFeasibility Program"). All data used in the study were compiled thanks to the agreement of the Corporate Coke Lab belonging to ArcelorMittal Ostrava company.

\section{REFERENCES}

Barriocanal, C., Díez, M.A., Alvarez, R., Casal, M.D. and Canga, C.S.: 2003, On the relationship between coal plasticity and thermogravimetric analysis. J. Anal. Appl. Pyrolysis, 67, No. 1, 23-40.

DOI: 10.1016/S0165-2370(02)00012-8

Chaudhuri, S.G., Mukherjee, A.K. and Roychoudhury, K.K.: 1990, Relation between physico-chemical and petrographic properties of Indian coking coal. Proceedings of National Seminar on Coal for Blast Furnace Coke and for Injection, Jamshedpur, 65-76.

de Cordova, M., Madias, J. and Barreiro, J.: 2016, Review on modeling of coals blends for prediction of coke quality. AISTech 2016 Proceedings of the Iron \& Steel Technology Conference, May 16-19, Pittsburgh, PA, USA: AIST, 297-309.

Díaz-Faes, E., Barriocanal, C., Díez, M.A. and Alvarez, R.: 2007, Characterization of different origin coking coals and their blends by Gieseler plasticity and TGA. Journal of Analytical and Applied Pyrolysis, 80, No. 1, 203-208. DOI: 10.1016/j.jaap.2007.02.008

Díez, M.A., Alvarez, R. and Barriocanal, C.: 2002, Coal for metallurgical coke production: predictions of coke quality and future requirements for cokemaking. International Journal of Coal Geology, 50, No. 1-4, 389-412. DOI: 10.1016/S0166-5162(02)00123-4

Flores, B.D., Borrego, A.G., Diez, M.A., da Silva, G.L.R., Zymla, V., Vilela, A.C.F. and Osório, E.: 2017, How coke optical texture became a relevant tool for understanding coal blending and coke quality. Fuel 
Process. Technol., 164, 13-23. DOI: 10.1016/j.fuproc.2017.04.015

Gupta, S., Shen, F., Lee, W.J. and O'Brien, G.: 2012, Improving coke strength prediction using automated coal petrography. Fuel, 94, 368-373. DOI: $10.1016 /$ j.fuel.2011.09.045

Jöreskog, K.G., Klovan, J.E. and Reyment, R.A.: 1976, Geological factor analysis, Elsevier, Amsterdam.

Klika, Z., Serenčíšová, J., Kožušníková, A., Kolomazník, I., Študentová, S. and Vontorová, J.: 2014, Multivariate statistical assessment of coal properties. Fuel Process. Technol., 128, 119-27. DOI: 10.1016/j.fuproc.2014.06.029

Koszorek, A., Krzesińska, M., Pusz, S., Pilawa, B. and Kwiecińska, B.: 2009, Relationship between the technical parameters of cokes produced from blends of three Polish coals of different coking ability. Int. J. Coal Geol., 77, No. 3-4, 363-371. DOI: $10.1016 /$ j.coal.2008.07.005

Krzesińska, M., Pusz, S. and Buszko, R.: 2002, New approach to evaluation of coke quality. Proceedings of 18th of Annual Meeting of the TSOP, Houston, Texas, USA, 63-67.

Kumar, P.P., Barman, S.C., Singh, S. and Ranjan, M.: 2008, Influence of coal fluidity on coal blend and coke quality. Ironmak. Steelmak., 35, No. 6, 416-420. DOI: 10.1179/174328108X335113

Lech, K., Jursova, S., Kobel, P., Pustejovska, P., Bilik, J., Figiel, A. and Romański, L.: 2017, The relation between CRI, CSR indexes, chemical composition and physical parameters of commercial metallurgical cokes. Ironmak. Steelmak., 133, 1-9.

DOI: $10.1080 / 03019233.2017 .1353764$

Leonard, D.C., Bonte, L., Dufour, A., Ferstl, A., Raipala, K., Schmole, P., Schoone, E.E., Verduras, J.L. and Willmers, R.R.: 1996, Coke quality requirements of European blast furnace engineers (joint EBFC-Paper). Proceedings of 3rd International Cokemaking Congress, September 16-18, Gent, Belgium, 1-10.

Menéndez, J.A., Álvarez, R. and Pis, J.J.: 1999, Determination of metallurgical coke reactivity at INCAR: NSC and ECE-INCAR reactivity tests. Ironmak. Steelmak., 26, No. 2, 117-121. DOI: $10.1179 / 030192399676997$

Miura, Y.: 1978, The science of cokemaking technology and its development in Japan, The Coke Oven Managers' Association (COMA) Year-Book, Mexborough, 292311.

North, L., Blackmore, K., Nesbitt, K., Hockings, K. and Mahoney, M.: 2017, A novel approach to coke strength prediction using aelf organizing maps. DMIN'17 - The 13th International Conference on Data Mining, Las Vegas, USA: CSCE.

North, L., Blackmore, K., Nesbitt, K. and Mahoney, M.R.: 2018, Models of coke quality prediction and the relationships to input variables: A review. Fuel, 219, 446-466. DOI: 10.1016/j.fuel.2018.01.062

Prasad, H.N., Karmakar, R.S., Tiwary, M., Singh, B.K. and Dhillon, A.S.: 1996, Possibility of eliminating coke cutting in case of stamp charged coke. Tata Search, 2, $52-57$.

Pusz, S. and Buszko, R.: 2012, Reflectance parameters of cokes in relation to their reactivity index (CRI) and the strength after reaction (CSR), from coals of the Upper Silesian Coal Basin, Poland. Int. J. Coal Geol., 90-91, 43-49. DOI: 10.1016/j.coal.2011.10.008

Pusz, S., Krzesińska, M. and Koszorek, A.: 2003, Porosity, optical reflectance and dynamic elastic modulus of laboratory produced cokes related to properties of initial coals. Proceedings of 12th Int. Conf. Coal Science, Cairns, Australia, 2-6.

Pusz, S., Kwiecińska, B., Koszorek, A., Krzesińska, M. and Pilawa, B.: 2009, Relationships between the optical reflectance of coal blends and the microscopic characteristics of their cokes. Int. J. Coal Geol., 77, No. 3-4, 356-362. DOI: 10.1016/j.coal.2008.06.003

Sakurovs, R.: 1997, Direct evidence that the thermoplastic properties of blends are modified by interactions between the component coals. Fuel, 76, No. 7, 615621. DOI: 10.1016/S0016-2361(97)00049-5

Sakurovs, R., French, D. and Grigore, M.: 2007, Quantification of mineral matter in commercial cokes and their parent coals. Int. J. Coal Geol., 72, No. 2, 81-88. DOI: 10.1016/j.coal.2006.12.009

Suresh, A., Ray, T., Dash, P.S. and Banerjee, P.K.: 2012, Prediction of coke quality using adaptive neurofuzzy inference system. Ironmak. Steelmak. 39, No. 5, 363369. DOI: 10.1179/1743281211Y.0000000087

Tiwari, H.P., Banerjee, P.K. and Saxena, V.K.: 2013, A novel technique for assessing the coking potential of coals/coal blends for non-recovery coke making process. Fuel, 107, 615-622. DOI: $10.1016 /$ j.fuel.2012.12.015

Todoschuk, T., Price, J.P. and Gransden, J.F.: 2004, Development of coke strength after reaction (CSR) at Dofasco. Iron. Steel Technol., 1, No. 3, 73-84.

Van Krevelen, D.W.: 1993, Coal: Typology - Physics Chemistry - Constitution, 3rd ed. Elsevier, Amsterdam.

Zhang, Q., Wu, X., Feng, A. and Shi, M.: 2004, Prediction of coke quality at Baosteel. Fuel Process. Technol, 86, No. 1, 1-11. DOI: 10.1016/S0378-3820(03)00058-4

\section{STANDARDS}

ASTM D388-05, Standard Classification of Coals by Rank, ASTM International, West Conshohocken, PA, 2005.

ISO 1171: Solid mineral fuels - Determination of ash. Geneva: ISO Copyright office, 2010.

ISO 562: Hard coal and coke - Determination of volatile matter. Geneva: ISO Copyright office, 2010.

ISO 349: Hard coal - Audibert-Arnu dilatometer test. Geneva: ISO Copyright office, 1975.

ISO 501: Hard coal - Determination of the crucible swelling number. Geneva: ISO Copyright office, 2012.

ASTM D2639/D2639M-16, Standard Test Method for Plastic Properties of Coal by the Constant-Torque Gieseler Plastometer, ASTM International, West Conshohocken, PA, 2016.

ASTM D4326-13, Standard Test Method for Major and Minor Elements in Coal and Coke Ash By X-Ray Fluorescence, ASTM International, West Conshohocken, PA, 2013.

ISO 7404-5: Methods for the petrographic analysis of coals - Part 5: Method of determining microscopically the reflectance of vitrinite. Geneva: ISO Copyright office, 2009.

ISO 7404-3: Methods for the petrographic analysis of coals - Part 3: Method of determining maceral group composition. Geneva: ISO Copyright office, 2009.

ISO 18894: Coke - Determination of coke reactivity index (CRI) and coke strength after reaction (CSR). Geneva: ISO Copyright office, 2006. 